\title{
Modalidades de representación en tres documentales amazónicos peruanos
}

\author{
Emilio Bustamante \\ (Universidad de Lima)
}

Recibido: 12/3/2013

Aprobado: 15/4/2013

\begin{abstract}
Resumen: En este trabajo se analizan los logros y limitaciones de la representación de los indígenas amazónicos en tres documentales peruanos, cada uno de ellos realizado según una modalidad diferente. Se ha utilizado la clasificación de modalidades de representación documental propuesta por Bill Nichols. El énfasis está puesto en la ausencia y la necesidad de la autorrepresentación indígena en el documental peruano.
\end{abstract}

Palabras clave: Cine / documental / representación / indígenas / Amazonía

\section{Modes of representation in three documentaries Peruvian Amazon}

Aвstract: In this paper we analyze the achievements and limitations of indigenous representation in three documentaries Peruvian Amazon, each made by a different modality. We used the classification of modes of documentary representation proposed by Bill Nichols. The emphasis is placed on the lack and the need for indigenous self-representation in the Peruvian documentary.

Keywords: Cinema / documentary / representation / indigenous / Amazonia 


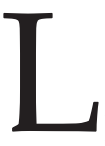

a Amazonía ha sido tema $\mathrm{y}$ escenario de varias películas peruanas desde décadas atrás (Cinencuentro 2011). En los últimos años han destacado en el país algunos documentales que plantean diferentes formas de representación de los indígenas amazónicos. Históricamente, los documentales sobre poblaciones originarias y sus costumbres han oscilado entre el exotismo (aún hoy practicado, especialmente por cadenas internacionales de televisión) y el objetivo antropológico. En este último caso, los filmes han evolucionado de la modalidad expositiva a lo observacional, y de allí a la interactiva.

Para la distinción de las modalidades nos basamos en Nichols (1997). El documental expositivo es aquel que hace uso de una estructura semejante a la de un filme clásico de ficción. Tiene comúnmente tres actos: en el primero se plantea el problema, en el segundo se debate y en el tercero se resuelve. Prima la palabra. Un narrador, a menudo omnisciente, ilustra al público sobre la cuestión y deja escuchar a especialistas, para al final emitir una conclusión que tiene fuerza de verdad revelada. A su estructura, a menudo acusada de autoritaria y logocéntrica, se opone el documental de observación, con largas tomas de registro y sonido directo, donde el documentalista aparentemente desaparece y los actores sociales fingen ignorarlo. Frente a la supuesta hipocresía de esta modalidad que oculta a un realizador que selecciona lo que se ve y escucha y rige - además - conductas ante la cámara, el documental interactivo (o participativo) plantea la intervención explícita del director para crear situaciones y permitir la acción espontánea de los actores sociales.

En los documentales antropológicos se pasó de los filmes con una voz over imbuida de sabiduría que describía a una audiencia occidental los hábitos, ritos o festividades de los indígenas, a documentales observacionales en una búsqueda de mayor objetividad en la representación, pero se cayó en una mirada vacía que era llenada fácilmente por la fascinación o el prejuicio. Entonces, los cineastas occidentales decidieron hacer participar al indígena en la realización de los audiovisuales, darle voz e iniciativa, e interactuar con él. Aun así, la mirada que prevalece en estos documentales participativos es la del documentalista. El indígena sigue siendo representado por otro. Representar a otro, y ser representado por otro, implica siempre una relación de poder. Surge así la demanda de la autorrepresentación. En algunos países de Latinoamérica se han llevado a cabo documentales donde las poblaciones originarias han intervenido en la producción, manejo de la cámara, edición y aprobación del resultado final. Esos documentales han servido para apoyar luchas reivindicativas o preservar la propia cultura mediante el registro de efemérides o actividades cotidianas (Carreño 
2007). No falta, sin embargo, también en estos casos, cuestionamientos a estas representaciones donde, de todos modos, participan instructores occidentales formados en un modo de representación institucionalizado por la cultura dominante, y entidades no gubernamentales con financiamiento extranjero.

Si bien en el Perú estas experiencias de representación son menos numerosas que en otros países, los documentales a los que aquí nos referiremos suponen ensayos plausibles y debatibles.

\section{Buscando el azul}

Fernando Valdivia es un comunicador social con una maestría en Estudios Amazónicos, como se lee en su blog Las rutas del Yashingo (Valdivia 2011). Es el realizador peruano que en los últimos años más se ha ocupado de temas amazónicos. Viaja constantemente a la selva y ha realizado con la empresa Teleandes los documentales Buscando el azul (2003), La travesía de Chumpi (2009) y Masato y petróleo (2009). En el 2011 estrenó Shipibo, la película de nuestra memoria, que tiene como eje el rescate de un antiguo filme antropológico norteamericano que registra a una comunidad shipiba. Aquí comentaremos Buscando el azul.

Buscando el azul es una película de 45 minutos sobre el pintor bora Víctor Churay, oriundo de Pucaurquillo (Loreto), quien plasmaba la historia, mitos, leyendas, y el presente de su pueblo, con tintes naturales sobre lienzos obtenidos de cortezas de árboles (llanchama). El filme comienza con Churay tratando de hallar el color azul natural. Luego de viajar a Lima y presentar con éxito una exposición de sus cuadros, Churay inicia estudios de historia en la Universidad Nacional Mayor de San Marcos, aunque se da tiempo para regresar a Pucaurquillo. El documental presenta testimonios de sus familiares y amigos, imágenes de sus pinturas, y al mismo Churay opinando sobre sí mismo, su labor y sus aspiraciones. La voz over de una narradora informa al inicio sobre el desplazamiento de boras de Colombia al Perú durante la época de la explotación de caucho; más adelante va relatando algunos incidentes en la vida del pintor, e incluso se permite opinar sobre la modernidad, la pobreza de las comunidades amazónicas y el peligro del olvido de conocimientos ancestrales. Churay confiesa, en una escena, sus aspiraciones políticas, y la búsqueda del azul se convierte entonces en un símbolo del deseo de protección y permanencia de su cultura. En la secuencia final, el artista se despide de su familia y su pueblo rumbo a Lima. En off se escuchan sus palabras: «Yo voy a regresar siempre, no tengo la fecha, ni el mes ni el año, pero yo voy a regresar acá, a Pucaurquillo». Un cartel nos revela, sin embargo, que el pintor murió en Lima poco después, a los 29 años, aparentemente víctima de un asalto. Tras unas imágenes en las que se le ve a la orilla del río en un 
atardecer a contraluz, aparece un último cartel: «Víctor Churay, el Azul que buscabas siempre estuvo en ti».

El documental ha ganado premios internacionales: el Premio Rigoberta Menchú en el III Encuentro Hispanoamericano de Video independiente «Contra el silencio, todas las voces» (México, 2004); y el Gran Premio Anaconda (La Paz, 2004) otorgado por el Programa Regional de Apoyo a los Pueblos Indígenas Amazónicos (Praia), el Consejo Latinoamericano de Cine y Comunicación de los Pueblos Indígenas (Clacpi), el Fondo Internacional de Desarrollo Agrícola (FIDA) y la Corporación Andina de Fomento (CAF). Fue elegido, asimismo, el mejor cortometraje de la Muestra Amazónica de Filme Etnográfico (Manaus, 2006).

Buscando el azul fue grabado durante varios años, y se terminó de editar después de la muerte de Víctor Churay. La imagen que resulta del protagonista es bastante positiva. Se trata de un joven pintor con conciencia social, amado por todos (paisanos y limeños), talentoso y estudioso de la historia de su pueblo, algo bohemio, con pretensiones políticas y sentido del humor. Sin embargo, aunque el pintor toma la palabra muchas veces, es muy evidente que la mirada es externa. Buscando el azul no deja de ser un documental expositivo donde se presenta a un personaje con una meta, se le sigue en su recorrido vital con testimonios propios y de gente cercana a él, y se cul- mina el relato con una afirmación contundente sobre dónde se encontraba el bien que buscaba. La voz over de la instancia enunciadora es omnisciente y poseedora de un saber cuasi divino que transmite a los espectadores. Esta instancia se manifiesta también en los carteles finales. No sabe únicamente el pasado de los bora, conoce además el itinerario vital de Churay y lo que se hallaba dentro de él (y que el mismo pintor parecía ignorar). Valdivia ha tratado de justificar la modalidad de representación elegida en una entrevista a Carlos P. Reyna:

Mi idea siempre fue que la voz sea del protagonista sin la participación de un narrador externo (en off) y de esta manera ser coherentes con la idea de mostrar una historia «desde el punto de vista indígena». En realidad tal «punto de vista indígena» no era posible en la medida que yo era el director y mi punto de vista cinematográfico construiría finalmente el discurso de Víctor Churay; yo sería el encargado de articularlo en un diálogo con mi propuesta narrativa. Creo que esa apuesta intercultural cinematográfica es la sinergia final del filme: un salto continuo entre el testimonio directo del protagonista y nuestra intervención como articuladores y contextualizadores en ciertos momentos (Reyna 2008).

En la misma entrevista, Valdivia añade: «[...] creo que el documental es una construcción conjunta con Víctor, un encuentro intercultural mediante el audiovisual gracias a nuestra mu- 
tua actitud dialogante». Pero, como el mismo director ha reconocido antes, es su punto de vista el que ha articulado finalmente el discurso de Víctor Churay. Un discurso que, además, el realizador considera que no era suficientemente articulado, por lo menos para presentarlo ante un público occidental:

En el documental confluyen varios discursos que en ciertos momentos son redundantes, en otros complementarios y en otros antagónicos dentro de una lógica dialéctica. La tradición comunicativa indígena peruana está marcada por la oralidad y los elementos simbólicos representados en su pintura corporal, los diseños que emplean, hasta por la manera de edificar sus casas o malocas. El punto de vista indígena que Víctor proponía en su trabajo está marcado no solo por los cuadros donde refleja su historia, cosmovisión y actualidad, también está marcado por su propia palabra, su voz, la cual él había aprendido a manejar mucho mejor que la mayoría de sus hermanos Bora debido a su presencia desde pequeño en la ciudad de Iquitos, donde trabajó como vendedor ambulante. Sin embargo eso no era suficiente, a veces articular una idea estaba acompañada de otras referencias que serían ricas para un investigador, pero que se convertirían en un ruido de comunicación al momento de llegar a un ciudadano común y corriente hacia donde Víctor quería dirigirse. En ese sentido mi papel fue ayudar a que sus ideas fuesen expresadas de manera clara y sintética. Las imágenes de su comunidad eran un complemen- to que el director se encargaría de articular libremente bajo la premisa de no manipularlas hacia algún sentido subalterno (Reyna 2008).

Si bien Valdivia es consciente de la multiplicidad de discursos, se impone la tarea de darle un sentido tanto al discurso oral de Churay («mi papel fue ayudar a que sus ideas fuesen expresadas de una manera clara y sintética») como al discurso visual («las imágenes de su comunidad eran un complemento que el director se encargaría de articular libremente...»). El documentalista se erige así en intérprete del bora; en su representante ante el «ciudadano común y corriente hacia donde Víctor quería dirigirse».

Valdivia define con lucidez el tema de su documental como: «la aventura intercultural de un indígena que se valía no solo de un tinte sino de todos los colores para reflejar su historia a un mundo que la desconocía». Precisa que en Churay existía «la necesidad de visibilizarse mediante cuadros que reflejaran su cosmovisión y su realidad actual». No deja de ser interesante, sin embargo, reparar en el hecho de que Churay representaba a su pueblo y a sí mismo directamente con su pintura. Aunque muy probablemente necesitó mediadores para exponer en Lima, hasta donde sabemos, ningún pintor limeño modificó sus cuadros para hacerlos más accesibles al público citadino al que Churay quería llegar. En el video, en cambio, él, su pueblo y su cultura, son representados por 
otro, su discurso verbal es adaptado, y las imágenes de su comunidad son registradas, compuestas y articuladas por ese otro. Si la representación es también un ejercicio de poder, Churay como pintor tenía un poder directo; como sujeto representado en el documental tiene - en el mejor de los casos- un poder delegado. Quien ejerce realmente el poder en el documental es Valdivia, no Churay.

Valdivia no desconoce, sin embargo, la opción de dar a los indígenas la posibilidad de realizar sus propios filmes, pero invoca dificultades logísticas y falta de interés institucional en el país para este tipo de experiencias:

Desde el año 96 trato de que se rompa ese monopolio de los occidentales que hablan o reflejan el mundo indígena. En ese año empecé a trabajar esporádicamente capacitando indígenas del Perú y otros países en la apropiación del medio audiovisual para que ellos hablen de sí mismos, se auto-reflejen y construyan frente al mundo su propia realidad y quizás para que construyan desde su propia perspectiva visiones de quienes antes hablaban de ellos: la gente de las grandes ciudades. En el Perú no hay un gran desarrollo en el audiovisual indígena como sí existe en Bolivia, Brasil, Ecuador, México y otros, no hay un interés endógeno sostenido, por ello nos hemos limitado a pequeños talleres sin continuidad debido a las dificultades logísticas para continuarlos fuera de Lima. Actualmente soy un practicante del documental participativo durante el rodaje y algunos aspectos del guión, teniendo siempre claro que soy el director y finalmente yo debo decidir en la versión final (Reyna 2008).

Valdivia sugiere que tanto en el rodaje como en el guion de Buscando el azul se habría optado por la modalidad participativa; el resultado, sin embargo, es un documental expositivo, donde las iniciativas de participación de los actores sociales aparecen minimizadas. Más cercano a la modalidad participativa es Brus Rubio (2009), otro documental sobre un pintor indígena, dirigido por Carlos Sánchez Giraldo y Sofía Velázquez Núñez, del colectivo Mercado Central.

\section{Brus Rubio}

Brus Rubio dura 26 minutos y fue premiado en el Cuarto Concurso Extraordinario de Cortometrajes de Conacine. Forma parte de una trilogía de cortos documentales realizada por Mercado Central para el programa Las partes del todo del Canal (á) de Argentina. Los otros cortos son Vine cargando mi arpa y El otro cine. En cada uno de los tres se toma como personaje central a un artista popular: el pintor Brus Rubio Churay en el primero, la arpista y cantante Laura Pacheco Quisca en el segundo, y el cineasta Lalo Parra Bello en el tercero. El resultado es una mirada sobre la vitalidad y variedad del arte popular peruano actual. 
Brus Rubio Churay (nacido en 1984), pintor huitoto-bora de mitos y sueños con exposiciones en Lima, hábil fisga (pescador), nacido y residente de Pucaurquillo, primo de Víctor Churay, había participado ya en otro filme, el largometraje de ficción El perro del hortelano (2009), dirigido por Renzo Zanelli Barreto y producido por Magic Flute Films y Selva Rica Coop. Allí interpretaba precisamente a un joven artista indígena, de nombre Brus. El filme pretendía denunciar a las empresas petroleras depredadoras, a representantes de la Iglesia católica, a las posturas desarrollistas y al gobierno de los Estados Unidos, pero lo hacía con maniqueísmo e ingenuidad. Según los créditos, Brus Rubio intervino en la elaboración del guion con actores, directores y productores. Su actuación es, en general, convincente; pero, en ocasiones, recita parlamentos evidentemente escritos por otros. Frente a la representación ficcional de El perro del hortelano, el documental de los directores de Mercado Central parecía ofrecer al pintor huitoto-bora la oportunidad de representarse a sí mismo y hacer escuchar su propia voz.

En efecto, durante el filme se escucha bastante a Rubio. Una frase suya abre el relato: «Quinientos años de conquista. No estamos todavía perdidos. Existimos. Existo yo todavía». Las imágenes que siguen recuerdan a Buscando el azul: estamos otra vez en Pucaurquillo, habla la madre del artista, vemos algunas de sus obras, y él bromea con sus amigos y conversa con otros pintores. La tarea de Rubio es reconocida en palabras de su madre («Protege nuestras costumbres para que no se olviden. Lo que ve, pinta. Lo que sueña, también pinta»), y el artista reivindica la importancia de la maloca en la transmisión y reproducción cultural de la comunidad. La estructura del documental, sin embargo, es distinta a la de Buscando el azul: la narración es más libre, el personaje no tiene un objetivo concreto dentro del relato, $\mathrm{y}$ no existe voz over que nos ilustre sobre lo que vemos y articule causalmente la representación.

No se trata de un documental expositivo; pero la modalidad no es tampoco de observación, pues Rubio habla constantemente a la cámara, haciendo notoria a una instancia detrás de ella. Por momentos, inclusive, actúa como presentador - ante esta instancia- de sus colegas pintores Darwin Rodríguez Torres y José Asunción Araujo Guerra (Ashuco). La aparente libertad en el relato y la participación del personaje no significa la desaparición de la instancia (ni de la mirada de esta). Ella se manifiesta, además, a través de animaciones sobre cuadros del artista, interviniéndolos de algún modo. Al final, a semejanza de Buscando el azul, ese otro al que corresponde la mirada hace un comentario que cierra el discurso: «Brus Rubio vive en un lugar donde la gente pinta para alegrarse la vida. Él aprendió a ser artista cuando supo que afuera, 
más allá del río en el que pesca para comer, sus historias podían encantar».

La intención de los jóvenes realizadores citadinos que integran Mercado Central es hacer conocer artistas y manifestaciones artísticas populares contemporáneas a un público occidental y urbano. Construyen sobre ellos una mirada empática e invitan a los espectadores a que la compartan. La opción se aleja del documental de observación y se acerca a la modalidad participativa; pero esta no es realizada a fondo, pues los documentalistas intervienen menos de lo deseable, y ello impide ahondar en el conocimiento de los representados (muchos de sus códigos quedan en sombras, como los del mambeado y la maloca).

Por otro lado, si bien la modalidad participativa busca poner la mirada del realizador a salvo del paternalismo del documental expositivo clásico, no parece suficiente para eliminar del todo la jerarquía que existe entre quien conduce y otorga la participación, y quien se mueve dentro de los márgenes que el otro le permite. Si bien esta desigualdad entre representante y representado es lógica e inevitable en cualquier documental participativo, el asunto se complica cuando el realizador es un artista que actúa dentro de la cultura de elite y el representado un artista popular. Las imágenes creadas por el artista popular son incorporadas (e incluso intervenidas) por el orden simbólico de la otra cultura.
Paradójicamente, la jerarquía que se pretende romper, por el contrario, se consolida. La solución a ese problema es, en verdad, difícil. Probablemente pasaría por abrir más las puertas a la intervención, el diálogo y la participación, de modo que la forma misma del documental fuera invadida y modificada por el representado. Pero en ese caso ya estaríamos a las puertas de la autorrepresentación.

\section{La frontera}

La frontera (2010), de Salomón Senepo, es un documental de 52 minutos, realizado dentro de Doctv, un programa de fomento a la producción y difusión televisiva de documentales latinoamericanos. Previamente, el proyecto había ganado el concurso nacional de selección.

En La frontera vemos al inicio del filme que el cineasta Salomón Senepo Gonzales realiza un documental sobre los conflictos existentes entre asháninkas y colonos. En el transcurso, sin embargo, va descubriendo secretos que él mismo ignoraba sobre su propio origen e identidad.

Dividido en tres actos (como Buscando el Azul), en el primero el documentalista llega a Marankiari Bajo y entrevista a nativos asháninkas y colonos de origen andino. Informa que el centro poblado fue fundado en 1939 por los asháninkas, pero los colonos de la sierra que fueron llegando después 
son ahora mayoría. Los nativos acusan a los colonos de haberse apropiado indebidamente de sus tierras y los colonos reprochan a los asháninkas su falta de ambiciones. Queda claro que para los nativos el progreso no tiene la misma importancia que para los colonos. Senepo entrevista a una pareja mixta, en cuyo hogar se nota la influencia de culturas distintas. A continuación, el realizador deja escuchar su voz para hacer una revelación:

Durante las grabaciones fui comprendiendo que yo tenía una motivación personal para estar interesado en la situación social de Marankiari Bajo, pues sin ser muy consciente todavía me veía reflejado en el conflicto entre pobladores asháninka y colonos. Mi padre nació en Yurimaguas y sus antepasados son selváticos; mi madre es del Cusco, y desciende de españoles e indígenas andinos. Es decir que yo vivo dentro de mí el mismo conflicto entre andinos y amazónicos que se da en Marankiari Bajo.

Senepo confiesa, luego, haber vivido de espaldas a su linaje amazónico, y atribuye ello a que «en el Perú todos preferimos ignorar nuestro lado indígena y solo reconocemos nuestra parte extranjera por poca que esta sea». No obstante, recuerda que su padre dejó antes de morir un manuscrito con anécdotas de su vida y descripciones de la Amazonía, y anota su voluntad de encontrar ese texto al regresar de la selva porque «en él descubriría seguramente cosas sobre mi padre, sobre mis ancestros, y sobre mí mismo».
Antes de retornar, sin embargo, el documentalista constata mediante entrevistas realizadas en Marankiari Bajo que muchos nativos están perdiendo sus conocimientos, lengua y creencias originarias como efecto de la occidentalización. El documental, entonces, da un giro que nos introduce en el segundo acto. Senepo decide dirigirse al interior de la selva para indagar por la existencia de comunidades asháninkas donde aún se hable la lengua nativa y perduren las costumbres y creencias antiguas. Llega así a Shimuyani; allí los nativos, si bien visten ropas occidentales, se comunican entre ellos en su lengua y conservan saberes heredados de sus antepasados. En la escena culminante de esta parte del filme, Senepo baila con un joven líder de la comunidad, quien ha sido su anfitrión. El joven canta unos versos en su lengua mientras bailan: «Ya no, ya no, ya no lo voy a ver, / A mi amigo no voy a ver, / A mi amigo no voy a ver. / Estoy triste, estoy muy triste. / A mi amigo que está aquí, / Ya no lo voy a mirar. / Vuelve, vuelve otra vez, / Pero tienes que volver saltando».

Entonces el relato da un nuevo giro hacia una búsqueda más íntima de identidad. El documentalista relata que al regresar a Lima halló el manuscrito de su padre. Senepo, antes, se ha referido en el filme a las semejanzas entre él y su progenitor. Él es un camarógrafo viajero, y su padre, quien trabajaba como policía y tenía que cambiar de domicilio constantemente por razón de su oficio, llevaba siempre 
consigo una cámara, pues era aficionado a la fotografía. En el manuscrito rinde cuenta de la actividad que realizaba más allá de su labor policial. Se puede leer allí: «Para aumentar el dinero de mi pensión y no quejarme de la vida, trabajo de reporter gráfico. Capto imágenes increíbles, por eso me considero un historiador plástico». Guiado por el texto de su padre, el documentalista decide viajar a Yurimaguas en busca de sus raíces, donde conoce a algunos de sus parientes y recaba información sobre su familia. Un comunero lo ilustra: «Han sobrevivido a estos siglos de dominación, cuatro grupos aquí en San Martín: los tabalosos, los lamistas, los chasutinos y los moyobambas».

De regreso nuevamente en Lima descubre, en un libro, una relación de indígenas tabalosos del siglo XVII donde figura el apellido Chasnamote, segundo apellido de su padre. Luego de comunicarse con el editor del volumen, recibe de parte de este la transcripción de un documento de 1663 donde se menciona al cacique tabaloso Juan Senepo. La voz del director concluye: «Una nueva etapa en la búsqueda de mis orígenes se iniciaba».

La voz over del cineasta parecería describir un proceso que se fue dando durante la realización del filme. Pero, en realidad, no ocurrió así. En el proyecto presentado a Doctv ya se reseñaba, en lo esencial, ese proceso de autoconocimiento llevado luego a las imágenes, de modo que hay un cierto grado de representación ficcional en la película. Sin embargo, Senepo sí experimentó un cambio en el conocimiento de sí mismo y sus ancestros amazónicos, y ese tránsito de la ignorancia (o la negación) al saber (y el reconocimiento) no careció de conflicto. Lo que sucede es que el proceso comenzó antes de realizado el documental, durante la etapa de investigación que condujo a la elaboración del proyecto.

Este fue realizado con el aporte del guionista Jaime Luna Victoria, quien no solo sugirió la estructura del relato y la definición de la modalidad del documental, sino que también actuó como interlocutor del realizador en el curso de la indagación que este iniciara sobre sus orígenes amazónicos. $\mathrm{La}$ frontera, en realidad, es el producto de un proceso de autoconocimiento que se inició antes de que empiece el rodaje, continuó durante este, y permanece abierto. Planteado inicialmente como un proyecto de documental expositivo sobre los conflictos entre nativos y colonos, derivó en un proyecto que adoptaba lo que Bill Nichols denomina modalidad performativa. Para Bill Nichols, el documental performativo indaga por la complejidad del conocimiento del mundo, resaltando la dimensión subjetiva y afectiva, enfatiza la complejidad emocional de la experiencia y la memoria, y adopta un carácter autobiográfico a menudo bajo la forma de un diario del cineasta (Nichols 2001). Las críticas a esta modalidad enfatizan el excesivo subjetivismo que puede derivar de ella. 
Senepo trata de mantener un cierto equilibrio entre la mirada indagadora hacia la cultura de los indígenas y la que dirige a sí mismo, pero el interés del relato se inclina por su aventura personal de construcción de identidad, que - es verdad - alude a la de muchos peruanos.

Aunque en los tres documentales hay una intención valorable de representación, las modalidades empleadas establecen también los límites de ella. En todas, sin embargo, predomina la mirada occidental de los cineastas. Es válido esperar próximamente documentales realizados por los propios pobladores originarios que enriquezcan las miradas que sobre ellos tenemos.

\section{Bibliografía}

Carreño, Gastón (2007). «Miradas y alteridad. La imagen del indígena latinoamericano en la producción audiovisual». Tesis para optar el grado de magíster en Estudios Latinoamericanos. Santiago de Chile: Universidad de Chile, Facultad de Filosofía y Humanidades, Centro de Estudios Latinoamericanos,
2007. <www.cybertesis.cl/tesis/ uchile/2007/carreno_g/.../carreno_g. pdfSimilares $>$. [Consulta: 1 de diciembre del 2011].

Cinencuentro (2011). «La Amazonía peruana en el cine», en Cinencuentro. Viendo cine desde el Perú. Página web <http://www.cinencuentro. com/2011/11/13/amazonia-peru-cine/>. [Consulta: 1 de diciembre del 2011].

Nichols, Bill (2001). Introduction to documentary. Bloomington: Indiana University Press.

Nichols, Bill (1997). La representación de la realidad. Cuestiones y conceptos sobre el documental. Barcelona: Paidós.

Reyna, Carlos P. (2008). «Composição narrativa do filme Buscando el azul. Una entrevista com o cineasta Fernando Valdivia». <http://www. doc.ubi.pt/04/entrevista_04_reyna. pdf $>$. [Consulta: 1 de diciembre del 2011].

Valdivia, Fernando (2011). «Del autor, su rollo. Las rutas del Yashingo. Experiencias de filmación». <http://www.blogger.com/profile/03208927602242266554>. [Consulta: 1 de diciembre del 2011]. 